\title{
THE BIODEGRADABILITY AND MECHANICAL STRENGTH OF NUTRITIVE POTS FOR VEGETABLE PLANTING BASED ON LIGNOCELLULOSE COMPOSITE MATERIALS
}

\author{
Petronela Nechita, ${ }^{\mathrm{a} *}$ Elena Dobrin, ${ }^{\mathrm{b}}$ Florin Ciolacu, ${ }^{\mathrm{c}}$ and Elena Bobu ${ }^{\mathrm{c}}$ \\ Considering the mild degradation strength and the fact that it may be an \\ organic matter reserve for the soil, in the past years lignocellulosic \\ materials have been used as fibrous raw materials in the manufacture of \\ biodegradable nutritive pots for the seedling in vegetable containerized \\ production. This paper analyses the behavior of the nutritive pots made \\ from biodegradable composites for the vegetable seedling production \\ process, focusing on their mechanical strength properties and \\ biodegradability. It was found that the biodegradability of composite \\ materials obtained from a mixture of secondary cellulosic fibers, peat, \\ and additives, is strongly influenced by the presence or absence of the \\ rhizosphere effect and the synergistic relations set in the culture \\ substrate between the plant roots and microorganisms, which develop \\ permanently the recycling and solubilization of mineral nutrients. The \\ results showed that the presence in the substrate of some complex \\ populations made by heterotrophic bacteria favors full degradation of the \\ pulp and lignin contained in the substrate and pots composition. \\ Therefore, unlike the reference sample (plant-free), cultivated versions \\ exhibited an intense biodegradation on the account of rhizosphere effect.
}

Keywords: Biodegradable nutritive pots; Lignocellulosic materials; Secondary cellulosic fibres; Peat; Biodegradability; Seedling; Wet strength; Dry strength

Contact information: a: Pulp and Paper Research and Development Institute - SC Ceprohart SA Braila, RO-810019 Romania; b: University of Agronomic Sciences and Veterinary Medicine, Dept. of Horticulture, Bucharest, Romania; c: Gheorghe Asachi Technical University of Iasi, RO-700050 Romania *Corresponding author: E-mail:petronela.nechita@ceprohart.ro

\section{INTRODUCTION}

In the past years there have been serious concerns regarding the increasing use of plastics and their effects on the environment and public health in the long term. Synthetic polymers are based on non-renewable resources, are non-biodegradable, release dioxins by incineration, and require extensive volume for disposal. All of these aspects involve additional costs for solid waste management, which is driven by factors along the entire life cycle (US Government Office 1989).

Plant seedling biodegradable pots enable direct transfer of plants into soil in a normal growth position, without affecting the roots, and moreover such technology does not generate solid waste, as in case of plastic pots. In this system, the seedling growth support is transferred into the soil at the same time with the plant, and as a result of soil environmental factors (temperature, moisture, microorganisms, etc.) it starts to degrade, allowing the roots to penetrate its walls (Patent no.7-327507, 1995). The biodegradation 
is also strongly influenced by the presence of the rhizosphere effect and the nature of synergistic relations set in the culture substrate between the plant roots and cellulasic microorganisms that permanently develop the recycling and solubilization of mineral nutrients. This synergistic effect results in a different plant feedback regarding the degree to which the pot is biodegradable. At the same time, the biodegradation products are assimilating into the soil and improve its quality by means of humus generation, depending on the material composition (Abaecherli 2005).

Fibrous materials represent the main raw material for biodegradable nutritive pots, and have a key role in composite structure forming, strength properties development, as well as in the pots' biodegradability. Under these circumstances, the most used fibrous materials are: kraft pulps to achieve the needed strength of the structure; recycled pulp fibers, obtained from different waste used paper products that mainly function as consolidation material in structure forming; and peat consisting of vegetal material, including wood fibers in various degradation stages, that provides the porosity, adsorption and water retention capability of composite structure, as well as nutritive properties. Besides fibrous materials, the composite materials also include auxiliary materials aiming to adjust the nutritive pots biodegradability, to control mechanical strength of the structure, to set up an optimum balance of nutritive elements, and to assure the plant prophylaxis.

The composite materials should have suitable mechanical strengths in order to make a convenient support to the soil and plant during the seed germination and seedling growth time. However, following the seedling transfer into the soil, the support structure must disintegrate gradually in a determined period of time, in a manner that does not adversely affect normal plant growth.

The purpose of this study is to evaluate the behavior of biodegradable nutritive pots with different compositions in the vegetable seedling growth process.

\section{EXPERIMENTAL}

\section{Materials}

Peat

Oligotrophic red peat, consisting of sediments containing hygrophyte plants and moss, decomposed in an anaerobic environment for long terms (main characteristics are shown in Table 1). One could note the high water retention value (ISO 23714/2007) that is a result of its porous structure, varying strongly on account of the rate of decay and the plants it rises from.

\section{Recycled fiber}

Secondary fibre pulp, obtained by slushing, sorting, and cleaning of old corrugated containers (OCC). The physical-mechanical characteristics of sheets obtained from this recycled pulp are shown in Table 2. 
Table 1. Agrochemical Characteristics of Peat

\begin{tabular}{|c|c|}
\hline Characteristic & Value \\
\hline $\mathrm{pH}$ & 4.28 \\
\hline Water retention capacity, $\%$ & 430 \\
\hline Total soluble salts, $\%$ & 0.0089 \\
\hline \multicolumn{2}{|c|}{ Content of microelements } \\
\hline $\mathrm{P}_{-} \mathrm{PO}_{4}{ }^{3-}, \mathrm{ppm}$ & 8.20 \\
\hline Total $\mathrm{N}\left(\mathrm{N}-\mathrm{NO}_{3}{ }^{-}+\mathrm{N}-\mathrm{NH}_{4}{ }^{+}\right), \mathrm{ppm}$ & 44.5 \\
\hline $\mathrm{Ca}^{2+}, \mathrm{ppm}$ & 81.624 \\
\hline $\mathrm{Mg}^{2+}, \mathrm{ppm}$ & 32.879 \\
\hline $\mathrm{K}^{+}, \mathrm{ppm}$ & 20 \\
\hline $\mathrm{Na}^{+}, \mathrm{ppm}$ & 30 \\
\hline
\end{tabular}

Table 2 Characteristics of Secondary Fibers

\begin{tabular}{|l|c|}
\hline \multicolumn{1}{|c|}{ Characteristics } & Value \\
\hline Breaking strength, $\mathrm{kN} / \mathrm{m}$ & 3.35 \\
\hline Tear strength, $\mathrm{mN}$ & 600 \\
\hline Number of double folds & 57 \\
\hline
\end{tabular}

\section{Additives}

Within the experimental program, the following types of chemical additives were used: mineral salts as source of various chemical elements, a wet-strength resin, and waste from grape processing (bunching and peeling wastes that were dried and crushed as powder) as a biochemical aid and partial substitute for the fibrous material.

The chemical aid levels, which are chiefly aimed at maintaining a selected $\mathrm{N} / \mathrm{P} / \mathrm{K}$ ratio found in the biodegradable composite mass, is specific to certain plant species. Thus, the following salts were metered into the formulation: urea and dibasic ammonium phosphate - to release nitrogen and phosphorus; borax and ammonium molybdate - to release microelements as boron and molybdenum; zinc sulphate and copper sulphate for zinc and copper; and potassium nitrate to release potassium.

In order to improve the wet strength of the composite fibrous structure, a polyamide epichlorhidrinic resin - Kymene 611 was selected (Hercules International $\mathrm{GmbH})$.

\section{Methods}

Obtaining composite materials

Three compositional versions of biodegradable nutritive pots dedicated to producing the seedling material were obtained, as follows:

charge;

- M1 version: mixture of peat + cellulosic fibers (100\%) and chemical aid

- M2 version: mixture of peat + cellulosic fibers (85\%) and residue from grape processing;

- M3 version: mixture of peat and cellulosic fibers (100\%)

A charge of $6 \%$ wet strength resin (Kymene 611) was used in all the three compositional versions.

The nutritive pots were made as a conoid $(\mathrm{H}=6 \mathrm{~cm}, \mathrm{D}=6.5 \mathrm{~cm}, \mathrm{~d}=4.2 \mathrm{~cm})$ of $6.5-9.0 \mathrm{~g}$ weight by means of a pilot plant that operates based on the formation and 
dewatering system through die molding, following the stages illustrated in Fig. 1. The obtained nutritive supports were dried in an oven at a temperature of $105^{\circ} \mathrm{C}$ (Nechita et al. 2009).

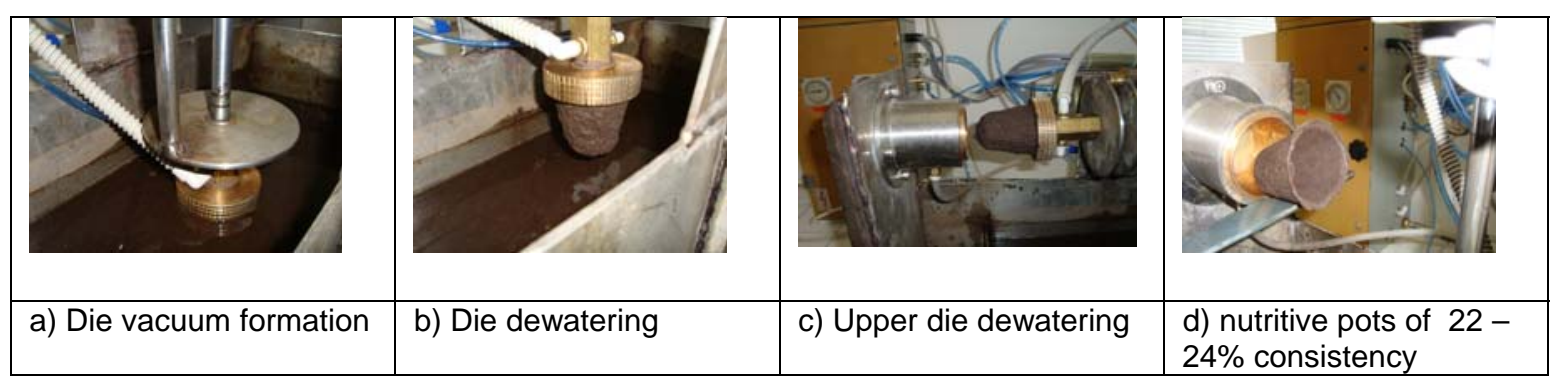

Fig. 1. Formation and dewatering of biodegradable nutritive pots

Pots obtained according to the M1 - M3 composition versions were tested for the wet and dry mechanical strength characteristics and biodegradability in contact with soil.

\section{Assessment of strength}

The mechanical strength properties are some of the most important for a composite structure, because regardless of their specific application, they should meet certain characteristics as regards shape, hardness, and strength. A specific device for strength evaluation, whose shape and construction is shown in Fig. 2, was developed in order to simulate the specific form and individual stresses that biodegradable nutritive pots are subjected to. It consisted of a penetrating die (1) that presses on the pot bottom and shapes both the gravitation force of the pot soil and the penetrating force of the roots. The biodegradable pot to be tested (4) is installed in a tapered piece (2) that shapes the hand holding system and retaining in the seedling handling operations. The piece (2) is centered ventrally with the penetrating die and is fastened on the compression plate of an Instron testing device that provides the plunger movement a steady speed of $100 \mathrm{~mm} / \mathrm{min}$ by means of the top clamp.

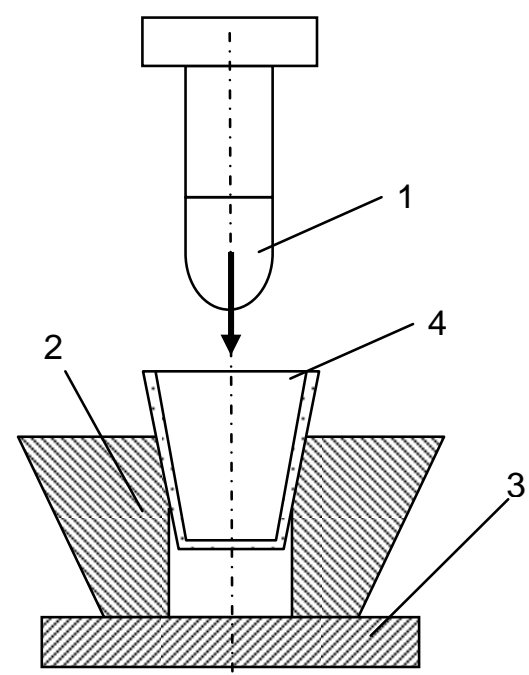

Fig. 2. Strength testing device for biodegradable nutritive pots: 1-penetrating die; 2- retaining tapered piece; 3- bottom plate; 4-biodegradable nutritive pot 
The resistance opposed to plunger advance is quantified by a sensor-transducer installed on the top clamp. The device continuously registers the penetration force, and at the end of the test the maximum value is displayed (Ciolacu et al. 2009).

Strength tests involving detachment of the base wall of the pots were carried out both on samples conditioned in the standard atmosphere $\left(23^{\circ} \mathrm{C}\right.$, moisture $\left.50 \% \mathrm{RH}\right)$ and wetted by water immersion at $23^{\circ} \mathrm{C}$ for 15 minutes.

\section{Biodegradability testing}

The biodegradability of nutritive pots was evaluated through the determination of the cellulasic degradation rate (Ştefanic 1999), using the following procedure: nutritive pot samples (dried at $105^{\circ} \mathrm{C}$ ) were incubated in a Terracult nutritive substrate used in producing seedlings. During incubation, tested nutritive pots were introduced in a previously weighed synthetic bag, in order to totally recover the fibrous material contained in it. During the entire experimenting period (141 days), the effective substrate moisture wherein pots were introduced was maintained in the range of 60 to $65 \%$ relative humidity, and temperature in the range 24 to $28^{\circ} \mathrm{C}$. Testing samples were regularly obtained by following method: the bag containing the sample was taken out of the substrate, flushed thoroughly, dried in the oven at $105^{\circ} \mathrm{C}$ for 4 hours, and then weighed. The biodegradation rate (degradation degree) was calculated as follows:

$$
\% \text { decomposed cellulosic material }=\frac{G i-G f}{G i-G s} \times 100
$$

$G i$-sample weight + bag weight before being introduced in the pot

$G f$ - sample weight + bag weight after taken out of pot

Gs - bag weight

Another indicator emphasizing the substrate biological activity is the capability to create a favorable environment for developing a typical microflora for soil and culture substrates. This indicator has been evaluated by microflora respiration intensity, having in view that microflora are involved in cellulosic material degradation (Szegi 1988). The experiments were carried out on both experimental nutritive pots and the current process for the production of lettuce (Lactuca sativa, var. Capitata) and tomatoes (Lycopersicum aesculentum) seedlings.

\section{RESULTS AND DISCUSSIONS}

\section{Strength Properties}

The strength tests performed by the method presented above provide relative results such as the maximum penetration strength, as well as a series of information provided by the break shape.

In the case of wet pots testing, which is more suitable to the actual conditions of use, at least two types of penetration feedback have been observed (Fig. $3 a, b$ ). Figure $3 a$ shows the typical case when penetration of the nutritive pot bottom has been done by 
punching the pot bottom. On the other hand, penetration by bottom "cutting" or tearing is shown in Fig. $3 b$. Feedbacks type " $a$ " are for cases wherein the pot is insufficiently consolidated or when its strength is lost by wetting, while feedbacks of type " $b$ " correspond to a normal behavior wherein destruction takes place on the minimum resistance line of the pot (Ciolacu et al. 2009).

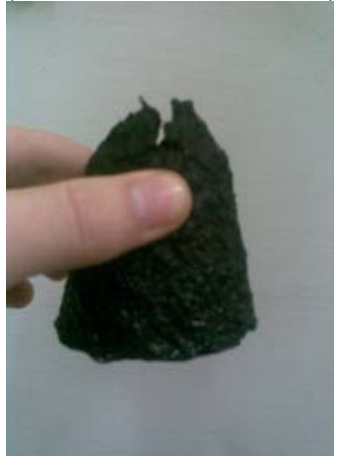

a)

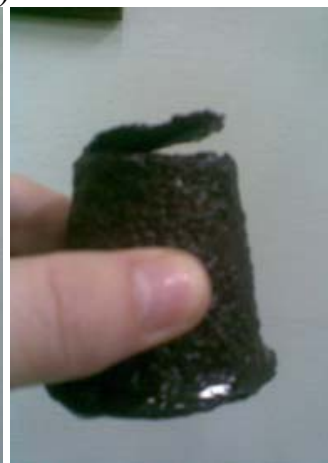

b)

Fig. 3. Different responses to strength test : a) - with punching of the pot bottom; b) - with "cutting" of the pot bottom

Figure 4 shows the results obtained after the strength tests involving detachment of the base wall of the pots.

As can be noticed, the M3 version developed the best strength properties, both in dry and wet testing. Values obtained for the series of M3 pots were between twice and three times higher than those registered for the other two series. It seems that in case of the M1 version, the nutrient charge as salts affected resin retention and crosslinking, as it is known that resin adsorption on fibers decreases significantly at the same time with increasing the valence of metallic ions and their stock concentration (Ampulski et al.1989; Roberts 1996; Yoon 2006). In case of the M2 version, the charge of residue from grape processing breaks the continuity of the fibrous network and introduces fine and colloidal anionically charged material. Nevertheless, in both cases (M1 and M2) the observed strength exceeds the strength requirement for handling and transport in the seedling manufacturing process.

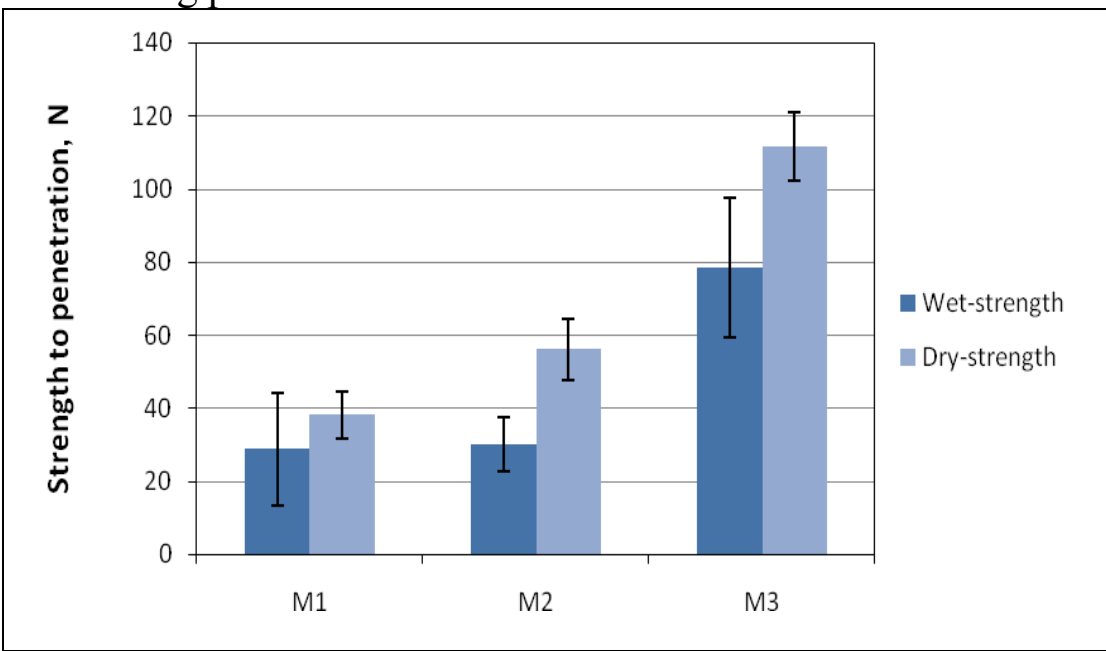

Fig. 4. Strength of resistance to penetration (dry and wet) of tested of nutritive pots 


\section{Potential and Effective Biodegradability}

As seen in Fig. 5, the following results stand out concerning the biodegradation potential of the tested nutritive pots: during the experimental program the M1 version pots showed the lowest biodegradation potential; though at the first analysis time (after 34 days), the M3 version pots showed a higher degradation rate (28.76\%), than the M1 and M2 pots, for the remaining analysis range a steady biodegradation rate was observed, so as at the end of the analysis range, the biodegradation potential was only $32 \%$.

In the last 14 days of the analysis range the biodegradation potential was the highest for the M2 version pots (44.19\%); this behavior can be explained by the fact that pots obtained with this composition contained a lower amount of fibrous material (85\%) compared with the M1 and M3 pots, and the residue from grape processing acts as a filler, increasing the distance between fibers and reducing bonding forces in the fibrous network. Thus the results obtained are correlated with the wet strength of the M2 version pots.

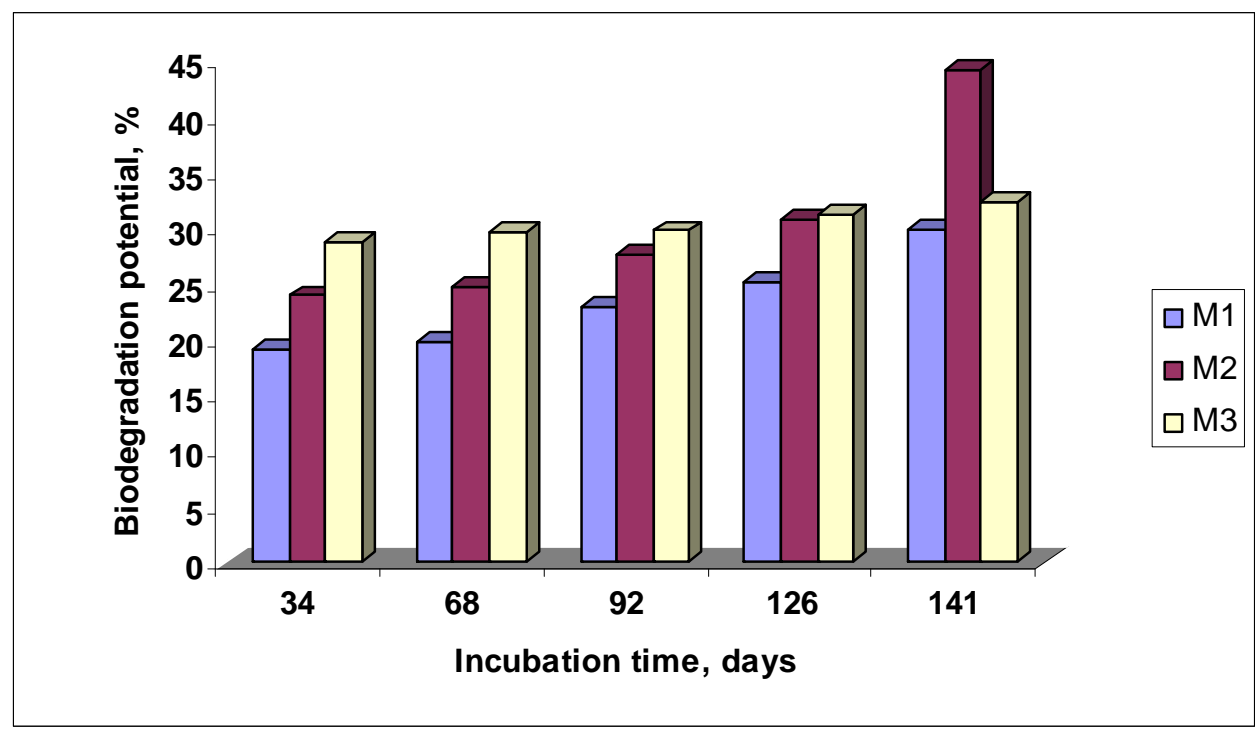

Fig. 5. Biodegradation potential for different times

The daily average biodegradation rate had the same development as the biodegradation potential. Accordingly, the M2 pots showed the highest daily average biodegradation rate (Fig. 6).

Regarding the actual biodegradation rate, calculated in the current process for producing tomato and lettuce seedlings, the three tested versions of pots behaved differently according to the seedling type (Fig. 7). Thus, in case of planting with tomato seedlings (after 51 days), the M1 pots exhibited the highest biodegradation rate $(16.48 \%)$, and the M2 version showed the lowest rate (15.35\%). When producing the lettuce seedlings, development was inverted (after 36 days of analysis). The reason is that tomatoes naturally have a stronger root system than lettuce, though the latter develops its roots faster. As result, the rhizosphere effect is intense in the case of tomatoes, and the biodegradation conditions are modified both in the culture substrate and in the pots. 


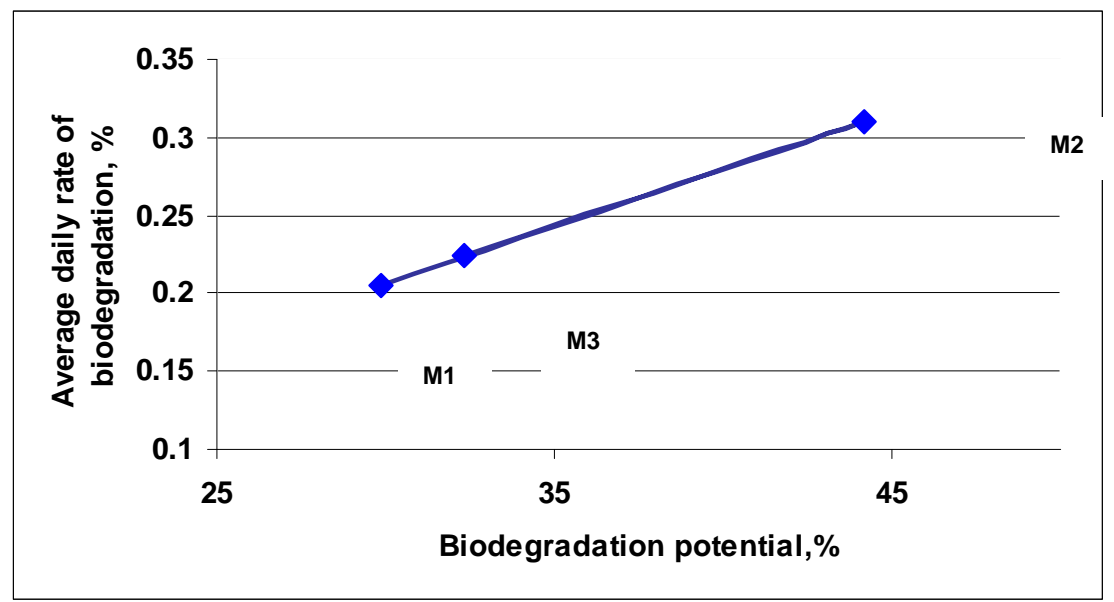

Fig. 6. Influence of nutritive pot type on biodegradation potential

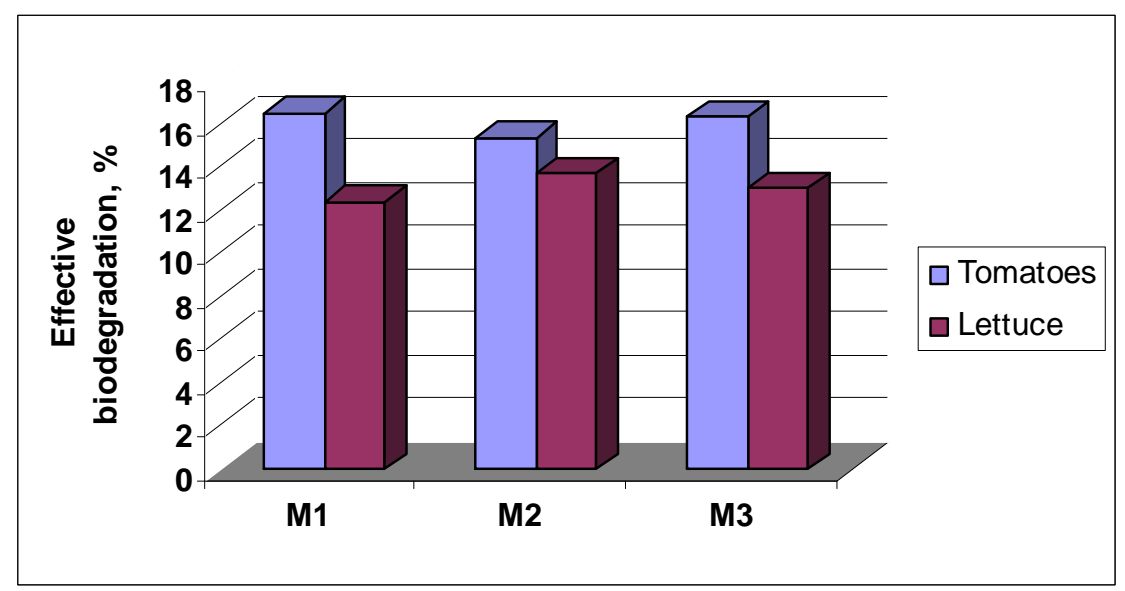

Fig. 7. Development of biodegradation rate related to nutritive pots in current process for seedling manufacturing

In the current process for seedling manufacturing, regardless of the species of seedling, for all the tested nutritive pots, the daily average biodegradation rate was much more intense (in case of planting), compared with case when pots were not planted and did not take advantage of the rhizosphere effect (Fig. 8). Concerning this aspect, differences occurred between two species, i.e., the daily average biodegradation rate for lettuce was 0.02 to $0.08 \%$ higher than for tomatoes, as result of the more intense occurrence of the rhizosphere effect, based on a previous higher lettuce root increases than in the case of tomatoes.

\section{Development Capability of a Medium Favorable to Installation of Soil and Culture Substrates Microflora}

In the area where roots are developing, the substrate physiology is different compared to where the substrate has been unexploited by roots. This difference is provided by the rhizosphere effect, consisting of growth stimulation and development of microorganisms around the roots due to root exudates released by the plant, as residues of its own metabolism. 


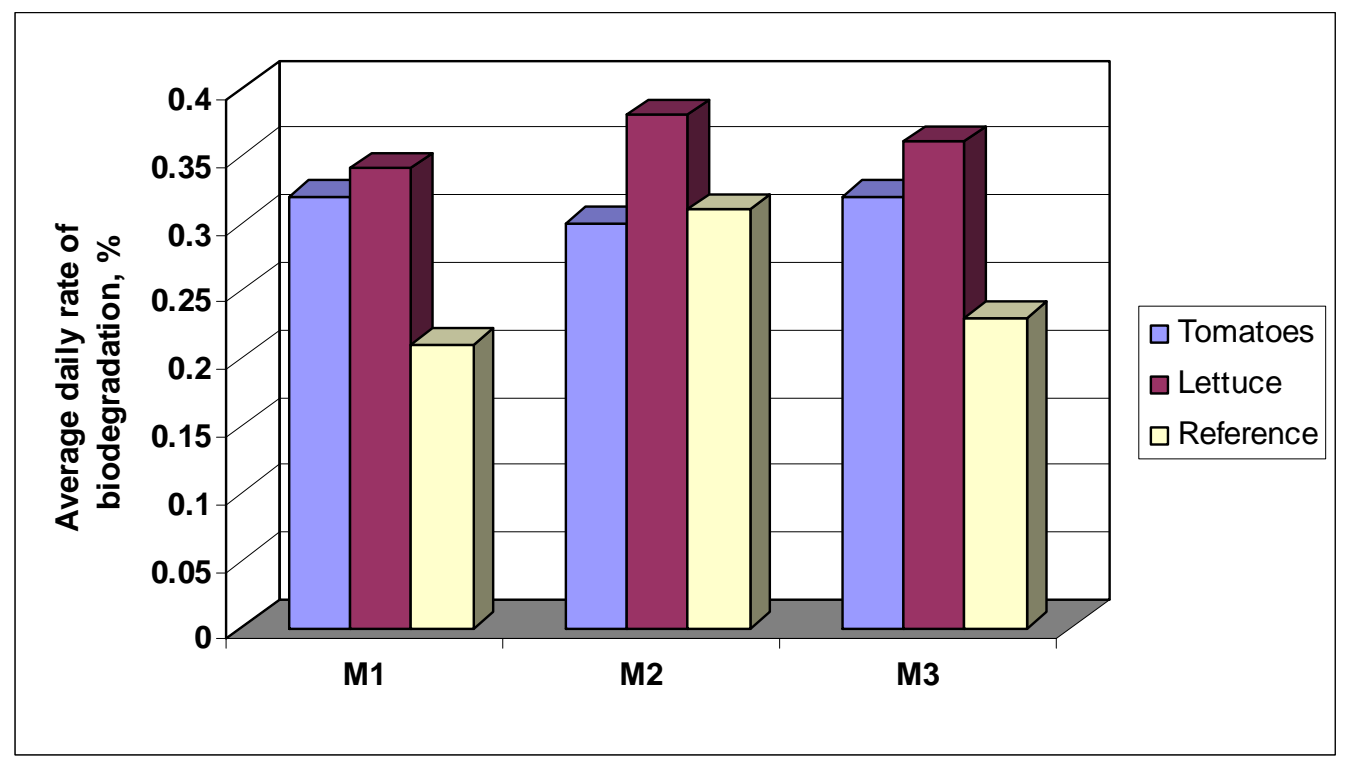

Fig. 8. Development of daily average biodegradation rate of nutritive pots cultivated on seedlings

When roots are very dense, as in the case of a substrate in a cultivated pots, the rhizosphere effect is supposed to encompass the entirety of the mass. The amount of exudates influences the size of microbial communities, and its quality shows the type of microorganisms. The chemical composition of the root exudates consists of glucides, amino acids, organic acids, vitamins, and growth factors (Rovira and Haris 1961; Hoffland et al. 1992; Zarnea 1994; Dakora and Phillip 2002).

Studying the biological activity, expressed as the $\mathrm{CO}_{2}$ amount released by microorganisms living in the tested nutritive pots substrate (Fig. 9), there was an apparent decrease of biological activity of pots with minerals in their composition (M1, M2) compared to the pots consist of only fibrous material (M3). This fact can be explained only by means of the extremely complex nature of relations set at the level of the culture substrate.

For the tested pot versions was observed that with respect to the level of respiration, there were differences from single to double between the cultivated and the non-cultivated substrate, especially in the case of the M3 version. In this case the plant cultivation led to a significant rise of intensity of respiration in the substrate, from approximately $26 \mathrm{mg} \mathrm{CO} / 100 \mathrm{~g}$ substrate d.s, for non-planted $\mathrm{M} 3$, to $35.3 \mathrm{mg} \mathrm{CO}_{2} / 100 \mathrm{~g}$ substrate d.s for M3 planted with lettuce and to $53.43 \mathrm{mg} \mathrm{CO}_{2} / 100 \mathrm{~g}$ substrate d.s for M3 planted with tomatoes. This aspect can be explained based on different intensities of the rhizosphere effect.

The rhizosphere effect has a different intensity according to the amount and quality of organic matter in the environment where plants grow. The literature mentions that in the soil rich in organic substances the rizosphere effect has no impact (Zarnea 1994); therefore, the biological activity of soil rich in organic matter is the same even if it is plant-cultivated or non-cultivated, while in a soil with a shortage of organic substances, 
biological activity is higher when the plants are cultivated than in the case of noncultivated soil.

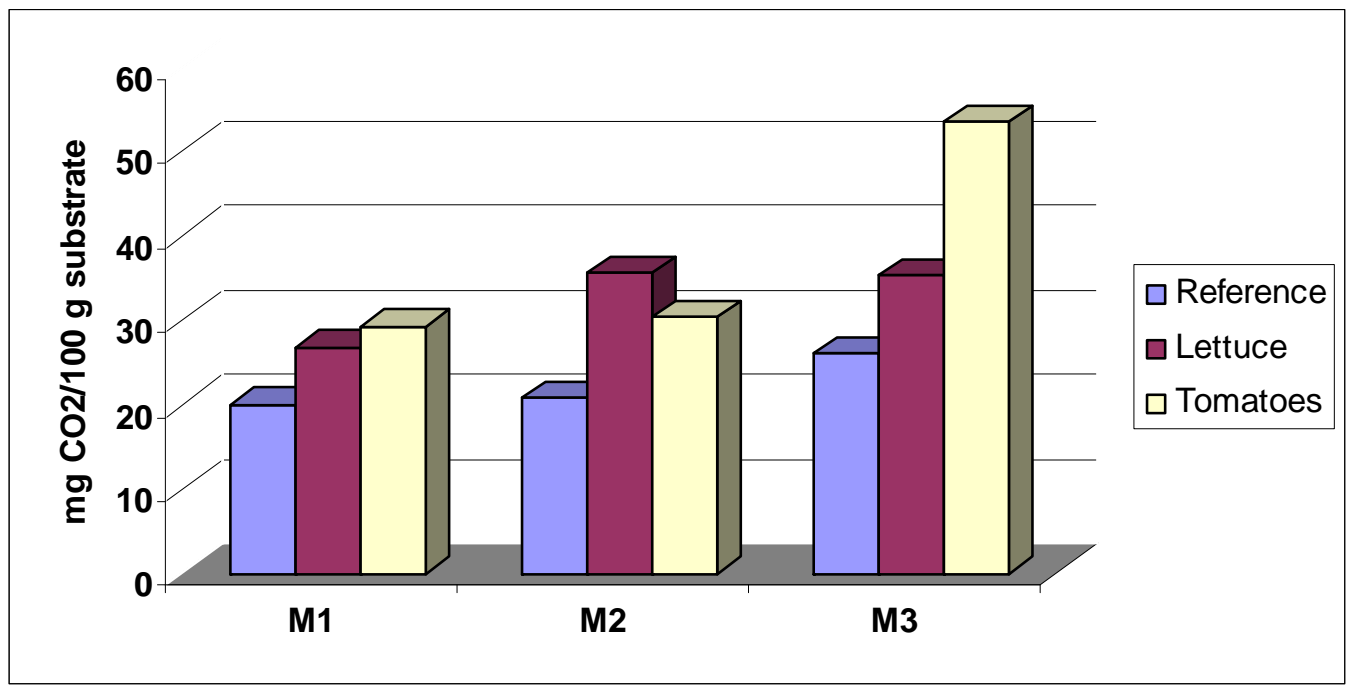

Fig. 9. Respiratory potential (mg CO $2 / 100 \mathrm{~g}$ substrate) of substrate in rhizosphere of lettuce and tomatoes

\section{CONCLUSIONS}

Following analysis of the results obtained within the experimental program carried out in this study, the following conclusions are drawn:

1. Biodegradable nutritive pots based on lignocellulosic materials can be used in the production of vegetables as an organic material reserve for soil; such applications are aligned with the European Directives concerning reduction of environmental pollution with plastics from agricultural sources by re-introducing in the ecosystemic cycle some important recyclable resources of organic matter: recovered paper and board, as well as residues from grape processing;

2. The mechanical strength test results (wet and dry) demonstrated the importance of fiber composition and chemistry relative to the formation of satisfactory biodegradable nutritive pots for the seedling production process;

3. A further charge of nutritive substances (mineral or organic charges) stimulates pulp degradation; therefore, the pots containing both chemical (for nutrient contribution) and natural (waste from grape processing) additives - M2 versionshowed the highest biodegradation rate;

4. In the current process for seedling manufacturing, regardless of species of seedling, for all the tested pot versions, the daily average biodegradation rate was much more intense, compared to the case when pots were not planted and did not benefit from the rhizosphere effect; 
5. Differences observed for the biodegradation rate in the case of planting nutritive pots with tomato seedlings compared to those planted with lettuce seedlings were due to the more intense rhizosphere (tomatoes has a native roots system stronger than that of lettuce), that change the biodegradation conditions both in the culture substrate and pot;

6. Based on the results obtained, it is considered that for M2 nutritive pots, process parameters related to maintaining biological stability have been met, since after 141 days, a biodegradation rate of around $45 \%$ was achieved with respect to both functions of the support for the plant and as a biologically active fertilizer;

7. For M1 and M3 pot versions, it is recommended to optimize the composition or the formation process parameters, aiming to increase the biodegradation potential, taking into consideration that in both cases the observed strength was higher than that required for handling and transport in the seedling production process.

\section{ACKNOWLEDGEMENTS}

The authors are grateful to Romanian Ministry of Education - National Scientific Research Agency, for financial support of project "Biocomposites from renewable resources - biodegradable nutritive support for containerized seedling manufacturing BIOSUN" Partnership within Priority Fields Programme, 2007 - 2010, contract $51090 / 2007$.

\section{REFERENCES CITED}

Abaecherli, A., and Popa, V. I. (2005). "Lignin in crop cultivations and bioremediation," Environmental Engineering and Management Journal 4(3), 273-292.

Ampulski, R. S., and Neal, C. W. (1989). "The effect of inorganic ions on the adsorption and ion exchange of Kymene $557 \mathrm{H}$ by bleached northern softwood kraft pulp," Nordic Pulp Paper Res. J. 2, 155-163.

Ciolacu, F., Nechita, P., and Bobu E. (2009). "Influence of composition and drying temperature on the properties of composite materials for biodegradable nutritive supports," Celuloză şi Hârtie, ISSN 1220-9848, 58(4), 12-18.

Dakora, F., and Phillips, D. (2002). "Root exudates as mediators of mineral acquisition in low-nutrient environments," Plant and Soil 245, 35-47.

Hoffland, E., et al. (1992). "Biosynthesis and root exudation of citric and maleic acids in phosphate-starved rape plants," New Phytol. 122, 675-680.

Nechita, P., Bobu, E., Ciolacu, F., and Dobrin, E. (2009). "Biocomposites from renewable resources - biodegradable nutritive support for containerized seedling manufacturing," National Research Programme, BIOSUN - Contract no. 51-090, stage $3 / 2009$.

Roberts, J. C. (1996). "Wet-strength additives," in Paper Chemistry, J. C. Roberts (ed.), Blackie Academic \& Professional, ${ }^{\text {nd }}$ Ed., 104-107. 
Rovira, A. D., and Harris, J. R. (1961). "Plant root excretions in relation to the rhizosphere effect," Plant and Soil 14, 199-214.

Szegi, J. (1988). Cellulose Decomposition and Soil Fertility, Akademiai Kiado, Budapest, 65-68.

Ştefanic, G. (1999). "Probleme de agrofitotehnie teoretică şi aplicată," vol XXVIII, Supplement, 45-50.

Yoon, S.-H. (2006). "Adsorption kinetics of polyamide-epichlorohydrin on cellulosic fibres suspended in aqueous solution," J. Ind. Eng. Chem. 12(6), 877-881.

Zarnea, G. (1994). Tratat de Microbiologie Generală, Vol. V, Ed. Academiei Române, 117-121.

*** Japan (Kokai) Patent No. 7-327507 / (1995).

*** U.S. Congress, Office of Technology Assessment, Facing America's Trash: What Next for Municipal Solid Waste, OTA-O-424 (Washington, DC: U.S. Government Printing Office, October p.183-188, (1989).

*** ISO 23714/2007 Pulps. "Determination of water retention value (WRV)."

Article submitted: March 4, 2010; Peer review completed: April 6, 2010; Revised version received: April 9, 2010; Article accepted: April 12, 2010; Published: April 14, 2010. 